\title{
Research on requirement elicitation model of high-end equipment based on requirement classification under Internet and big data environment
}

\author{
Yu GUO ${ }^{1, a}$, Junting WU ${ }^{1, b}$, Ke-wei YANG ${ }^{1, c}$, Lixin $Y u^{2, d}$ \\ ${ }^{1}$ College of Information System and Management, National University of Defense Technology, \\ Changsha 410073, China; \\ ${ }^{2}$ Science and Technology on Special System Simulation Laboratory, Beijing Simulation Center, \\ Beijing 100854, China \\ aguoyunudt@163.com, ’wujunting10@163.com, ckayyang27@163.com,634557505@qq.com
}

Keywords: high-end equipment; Internet; requirement elicitation; requirement classification

\begin{abstract}
Currently, Internet and big data as the representative of emerging technologies are widely penetrated into every aspect of the high-end equipment manufacturing industry. Considering the characteristics of multi-source, personalized and potential for high-end equipment, this paper focuses on requirement elicitation in the background of Internet, and proposes a high-end equipment requirement elicitation model based on requirement classification, which stands on the perspective of management to study the high-end equipment requirement elicitation. First, we classify the user's need, and then different technical means are taken orienting different types of needs . In this paper, according to users' master degree of requirement, requirements can be divided into instant user requirement and potential user requirement. For instant user requirement, we design a requirement interaction platform based on Internet; For potential user requirement, a requirement mining model based on the open source information of the Internet is established. Eventually, a complete user requirement program is integrated. In conclusion, the idea of classifying the requirements provides a new perspective on requirement elicitation of high-end equipment.
\end{abstract}

\section{Introduction}

The high-end equipment refers to that kind of technology equipment, which has high technology content, large capital investment, long service life, and involving many disciplines, generally requires the organization of cross-sectoral, cross-industry, cross-regional manufacturing power to complete, such as aviation equipment, rail transportation equipment, marine engineering equipment, intelligent manufacturing equipment etc. To cultivate and develop the high-end equipment manufacturing industry, which is a necessary demand to enhance the core competitiveness of China's industry. For accelerating the transformation of economic development mode and achieving the transformation of the manufacturing country to a powerful country have important strategic significance. The Chinese government also attaches great importance to the development of high-end equipment manufacturing industry, and issued a number of planning and policy measures to accelerate the industrial development of high-end equipment manufacturing industry.

The current situation investigation and development Strategy Research Report of 2014-2020 Chinese high-end equipment manufacturing industry have showed that manufacture a high-end equipment must base on user's requirement, and to meet the individual requirements is the starting point and ultimate goal of high-end equipment manufacturing. The strategic guidelines of "Chinese manufacturing 2025" also pointed out that we should make the work of requirement analysis and management in economic development and national defense construction clear. In addition,we should realize the transformation from "China manufacturing" to " China creation" with the combination of industrial technology and information technology. Therefore, the requirement elicitation of high-end equipment manufacturing is particularly vital. A market survey analysis report of high-end equipment manufacturing industry shows that the task of high-end equipment manufacturing construction's cycle is long, the system structure is complex, and also involves many 
factors. Therefore, customers are often difficult to present the "complete" requirement based on the actual situation, which is a major difficulty of the current requirement elicitation. At present, the Internet and the big data technology are widely applied, which allows users to express their wishes through more platforms and channels[1]. Which make it possible that high-end equipment manufacturing enterprises can get individual requirements information timely and accurately .

Currently, the methods of requirement elicitation is broadly divided into six categories: process-oriented, data-oriented, control-oriented, object-oriented[2], goal-oriented[3] and other methods. Generally, previous studies are only from the acquisition technology level to study simply, but in fact requirement elicitation is not only a technical problems, but also a management issues. Requirement elicitation is a complete process, it is necessary to study it from the perspective of management; Secondly, the combination of Internet and big data analysis technology with user requirement analysis technology to study is less, especially in requirement elicitation of high-end equipment manufacturing is blank. Therefore, it is necessary to study the requirement elicitation model of high-end equipment's customer in the background of the Internet big data. At present, global scientific and technological innovation presents a new trend of development, the Internet and big data as the representative of the emerging technologies are widely penetrated into all aspects of the production of products. Additionally, highly aggregation of space and information on Internet can make the enterprise to acquire the consumers' requirement more accurately and rapidlyIn other words, the use of Internet platform and big data analysis technology provide greatconvenience for enterprises to elicit requirement. This paper focuses on the Internet and big data technology background, combines with the characteristics of high-end equipment requirement, studys the requirement elicitation mode of high end equipment based on requirement classification, which providing a new perspective for the study of high-end equipment requirement elicitation.

\section{The characteristics and classification of user requirement of high end equipment under Internet and big data environment}

From a broad perspective to understand the requirement of high-end equipment products, it is that customer's need for products or services. This needs to be met by the products of enterprise manufacturing, but due to the information expression and acquisition is not complete, as well as the limitations of manufacturing conditions, enterprises can not fully grasp and meet this requirement, just can only be completed within a certain range of requirement response. In the high-end equipment product design and development process, the requirement analysis of high-end equipment manufacturing product is the first step of product design. There is a significant difference between high end equipment products and ordinary products, the user requirement will also have its unique characteristics.

\subsection{The characteristics of user requirement of high end equipment under Internet and big data environment}

High-end equipment manufacturing have higher complexity and integration, and the features of crossover and multidisciplinary integration are more obvious, which bring new challenges for requirement analysis of high-end equipment manufacturing. User requirement of high-end equipment mainly has the following features:

(1) Multi-source of user requirement

High integration and high complexity of High-end equipment products, which have variety of product information types, these information including business data and other operation maintenance data from enterprise internal and external Internet. About the requirement of high-end equipment products, the requirement data comes from diverse sources, including the direct user requirement, summary and enlightenment of product history information, technical requirements from technical department, user comment information on the Internet etc. These information has become an important source of requirement for high-end equipment manufacturing. In order to produce satisfactory products, enterprises must consider various information sources in the stage of product requirement elicitation. 
(2) Individualization of user requirement

High-end equipment manufacturing must be based on user's requirement, and meeting the individual requirements is the starting point and ultimate goal of high-end equipment manufacturing. which is the basic demand for the production of high-end equipment. The rapid development of the Internet and big data technologyprovide the timely ways for manufacturing enterprises to communicate with customers, which enterprise can identify the needs of customer quickly and accurately. According to customer's individual requirement, then realizing customization production at low cost. Individual requirements refers to the product and the service itself are customized according to customer needs, so it can avoid providing services do not conform to customer needs, and also reduce the waste of resources, therefore, rational allocation of resources can enhance the market competitiveness of enterprises.

(3) Potential of user requirement

Application background of high-end equipment product is complex, and production cycle is long that is about 3-5 years. Moreover, high-end equipment products are full of high technical content and technology product development dominates under the traction, user's expectation to the technology development is not enough, so users often cannot express specific requirements under investigation. A large number of Internet users' comment information and innovative technology development information have a potential value and the significance of mining, which from that information can dig up the authentic user potential requirement excactly, so as to guide the product development.

\subsection{The classification of user requirement of high end equipment under the Internet and big} data environment

The requirement of high-end equipment has the characteristics of multi-source, invidual and potential, and it also means that requirement elicitation of high-end equipment products will be a complex process. According to these characteristics, in order to obtain complete and accurate user requirement to design satisfactory products, it is necessary to classify the requirements and then adopt different technique methods to different requirements. This treatment can not only further simplify and clear the requirements process, but also can improve the efficiency and quality of requirement elicitation. User requirement classification also reflects the integrity of systems engineering ideas, which help to generate high-quality, full-range, accurate user requirement timely.

For different attributes of user requirement there are many different ways of classification. This paper consider the requirement to obtain in the Internet environment, depending on the master degree of users requirement can be divided into instant user requirement and potential user requirement.

Instant user requirement refers to that feedback of relevant product specific customization needs with time and the emergence of individual requirements, this part of requirement is mainly means the individual requirement of users; Potential user requirement is starting from the external environment, according to the development trend of similar products in the market and the emergence of innovative technologies, as well as the demand generated by user evaluation and other multi-source information channels, this part of requirements mainly refers to the users potential requirements mining from the Internet environment.

The instant user requirement of high-end equipment has some featuers, such as relatively clear requirement, strong real-time variability and relatively fixed source. Instant user requirement is the most direct form of user's personalized requirement, which is also the key measure of user satisfaction. On the contrary, potential users requirement of high-end equipment has some featuers, such as relatively not clear requirement, wide range of processing information, strong strength of information mining, which need certain techniques to dig out the relevant requirement information effectively and accurately from massive Internet user comments. 


\section{High-end equipment requirement elicitation model based on requirement classification under Internet and big data environment}

The core idea of high-end equipment requirement elicitation model based on requirement classification, is that according to the characteristics of different types of needs to take different means of requirements elicitation. The specific framework of the program is shown in Fig.

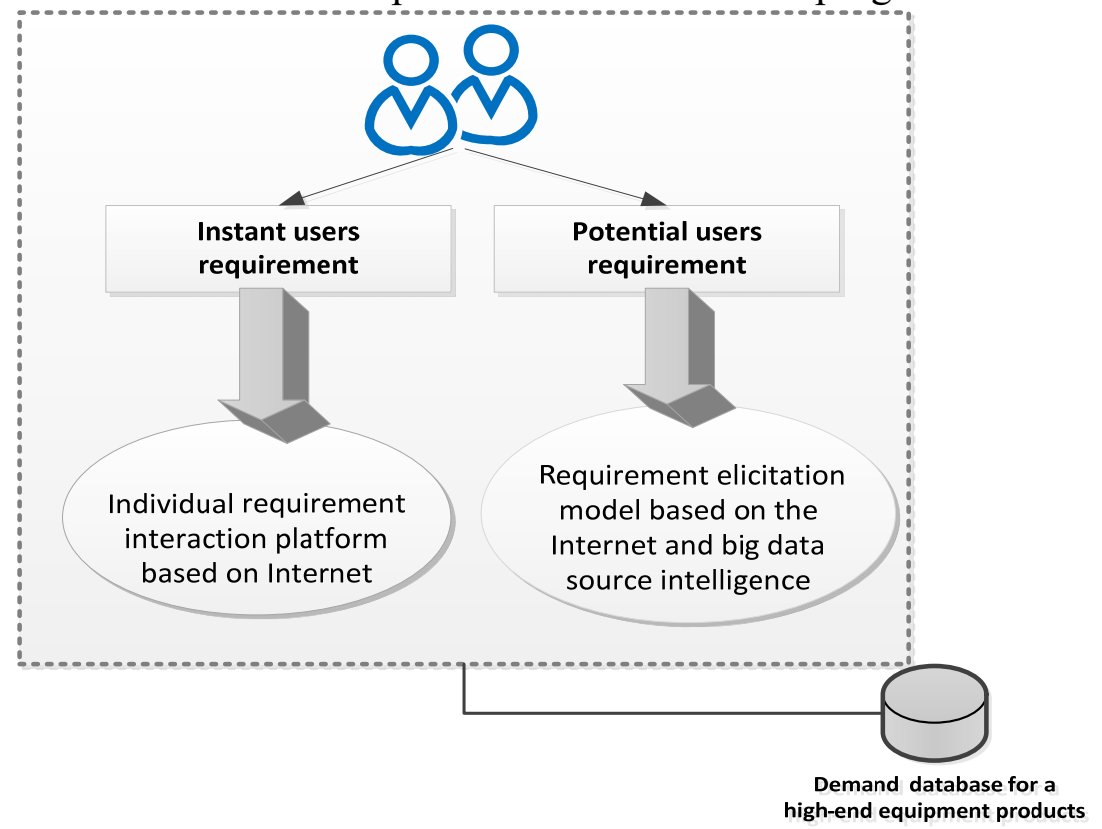

Fig.1. High-end equipment requirement elicitation model based on requirement classification

\subsection{The elicitation of Instant user requirement}

High-end equipment product's features are customization, single-batch, and small-scale production, its user terminal driving force is stronger, but which different from the traditional mass production products' user demand of diversification and decentralization. Therefore, how to efficiently obtain the personalized customization demand of high-end equipment, reflecting its dynamic change in real time and obtain the instant users' requirements, which is a very important part of high-end equipment requirement elicitation.

With the rapid development of Internet and big data processing technology, which make it more convenient and fast for the users and enterprise to get the information from each other.. More and more market users tend to achieve information preparation of products, custom design and evaluation process though Internet. Establish an high-end equipment requirement interaction platform based on the Internet, that is contributed to the specific individual requirements' elicitation in real time, interactive feedback and analysis management.

Traditional requirement acquisition method of instant user relies on repeated coordination between users and designers, which are time-consuming and inefficient. With the rapid development of Internet technology, it is possible to make the interaction technology based on the Internet platform. It can efficiently obtain the personalized customization demand of high-end equipment, reflecting the dynamic changes in real time and realize the interaction between users and developers.

High-end equipment requirement interaction based on the Internet that refers to users's interaction with related products and technical personnel in real time through network platform, which is developed by high-end equipment enterprisesreflects the individual requirements dynamically and participates in the process of product design and customization actively. .The most inportant point is to give personalized custonization according to user's dynamics. From the user's perspective, requirement interaction is kind of technology that can make the products reach the expected effective and enhance the customer satisfaction, it is committed to understanding the needs of individual users and to improve the enthusiasm and possibility of users to participate in the design. What's more, establishing a standard high-end equipment requirement exchange procedure is helpful for high-end equipment manufacturing enterprises to collect information of users' actions, psychological and 
behavioral features during interaction with product[5], and that as an important data storage for high-end equipment manufacturing requirements mining.

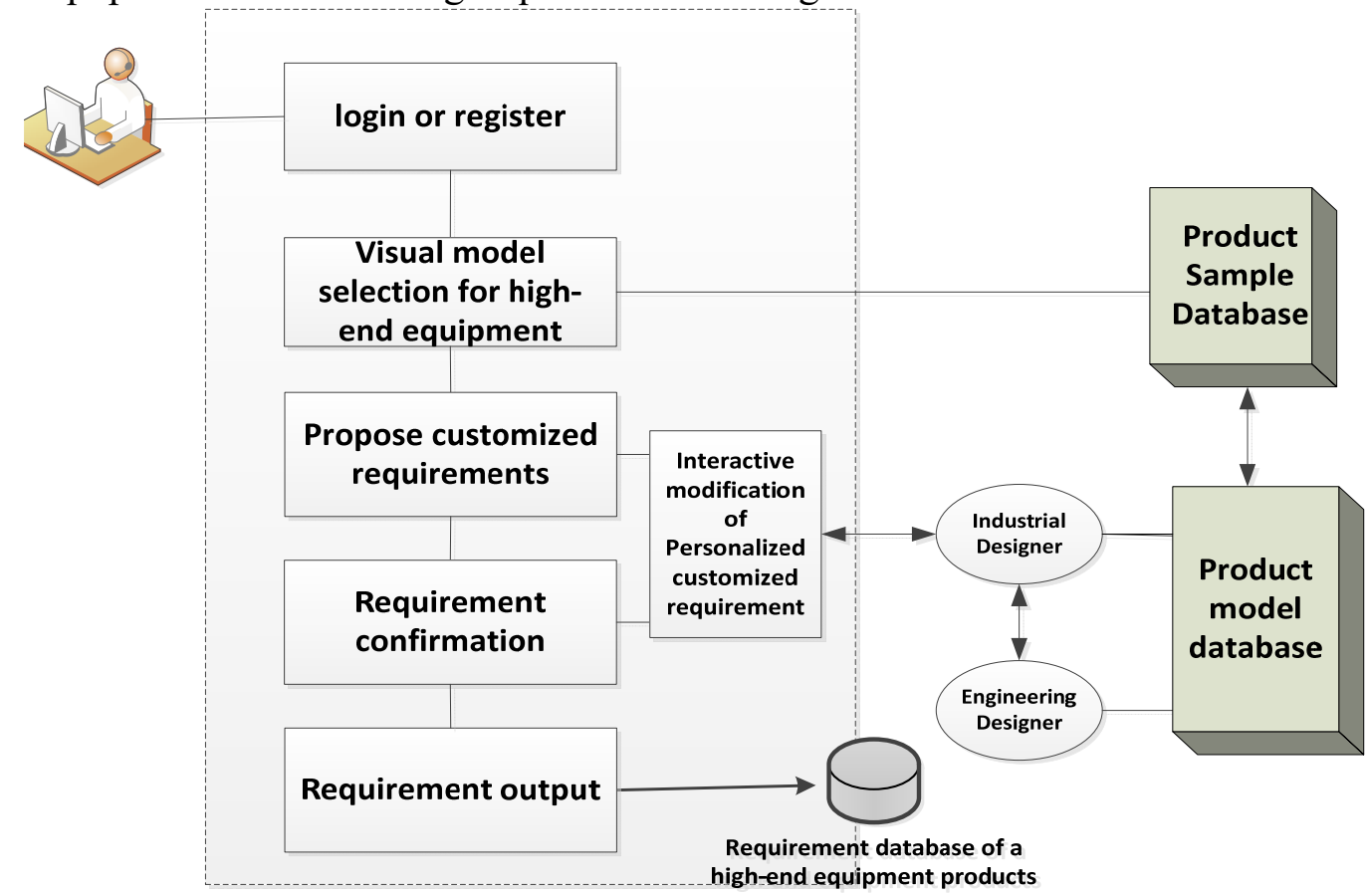

Fig.2. Requirement interaction platform based on Internet

On this basis, we need to achieve kind of functions like that establish three-dimensional online dynamic browsing of high-end equipment model based on Internet, preparation of basic parameter information of product and product design styling data, storage of requirement output ,etc. Product customization are completed on the network platform, where industrial designers and users communicate online in real time, then modified the details of program and implemented modularity by users and designers according to the requirements.

\subsection{The elicitation of Potential user requirement}

In recent years, the rapid development and application of Internet technology not only bring big change to business process, but also has a profound impact on users' behavior patterns. For high-end equipment products, more and more consumers are inclined to publish all kinds of comments about high-end equipment products on Internet, to express their experience in the use of the product and the desired relevant feelings. These comments may be distributed in high-end equipment professional forums, high-end equipment official website reviews, government documents etc. As the increasing maturity of web crawler mechanism, it makes this part of the Internet-based open-source intelligence become an important source of high-end equipment product requirements information. Requirements of high-end equipment is often implicit in these information, we can use big data mining techniques and machine learning method to extract potential customer requirements from this mass of large network data[4]. The techniques of potential user requirement elicitation include: VSM vector model representation for comprehensive evaluation information, SVM classification based on the requirement dictionary of high-end equipment, requirements mining based on the requirement semantic of high-end equipment, etc. The specific steps as shown below: 


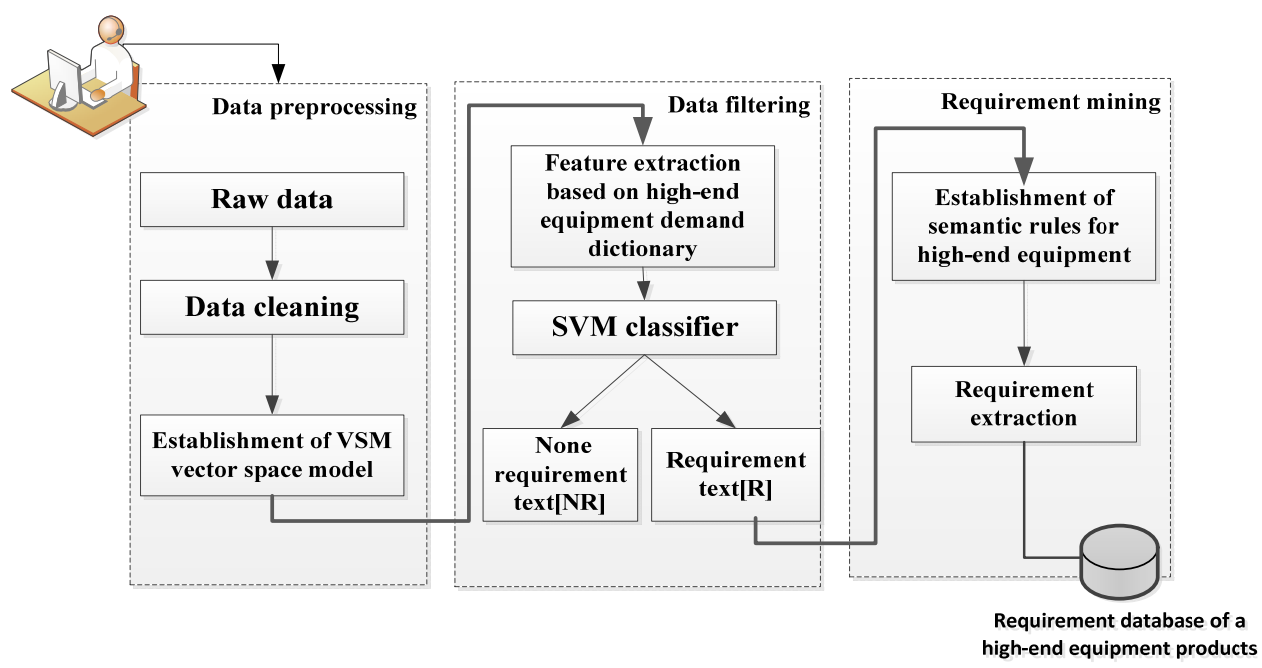

Fig.3. elicitation model of potential user requirement

Step 1: data preprocessing stage. We use existing crawler technology to crawl user reviews in specific network resources, and clean the crawled data. Since the web page is using HTML (Hypertext Markup Language) written, and semi-structured, and it contains certain tags and many links to other page in addition to the text we need. So raw data need to be normalized. In order to reduce the noise data and improve text representation quality, we must do preliminary data preprocessing work, including deleting some useless tag, text set segmentation, deleting stop words in text, Using VSM to represent text vector etc.

After data preprocessing, we obtain "clean" text and can transform the text-based data to vector-type data, which forms the fundation of further classification algorithm.

Step 2: data filtering stage. Data filtering stage refers to classify and recognize the text containing high-end equipment user requirements information on the internet, and filter out the text unrelated to high-end equipment requirements. In this step, we use the SVM classification method based on the high-end equipment requirements dictionary to process the text. Establish SVM classifier and divide text into two categories: None requirements text (marked as NR) and requirement text (marked as R). The most important feature of text vector is sparse and high dimensionality. Support vector machine has a large number of advantages for processing high-dimensional problem, so we choose SVM classification algorithm for text classification. Features extraction method for high-end equipment user requirement information classification based on requirement dictionary, Term Frequency-Inverse Document Frequency (TF-IDF) method are widely used in calculating the word weights. TF and IDF formula is as follows:

$$
\begin{gathered}
f_{i, j}=\frac{n_{i, j}}{\sum_{k} n_{k, j}} \\
i d f_{i, j}=\log \left(\frac{|D|}{\left|j: t_{i} \in d_{j}\right|}\right) \\
f i d f_{i, j}=t f_{i, j} \times i d f_{i}
\end{gathered}
$$

In the text , the weight of each word is not the same. It is obvious that the frequency of a word in this text is high and the frequency of occurrence in other text is low, so the weight of this word should be increased. On the contrary, a word appears in the text at a very small frequency and a lot of frequency appears in other texts., which take it for granted that the weight of word will be reduced. Therefore, through this method to calculate the weight of each word. In this research, we use the improved TF-IDF method, which is based on the TF-IDF method of high-end equipment requirement dictionary to carry out the feature extraction. For different high-end equipment products, the requirement dictionary will have a significant difference. So according to different high-end equipment to establish a relevant requirement dictionary[6]. The requirement dictionary contains some words that are often used to express requirements and the functional words of a particular 
high-end equipment. For the Beidou satellite, some words that often express requirements are "hope, demand, reduction, increase, improvement, want,"ect. It may involve some function words "positioning, navigation and timing services, short message communication ability" and so on, these two part words form the Beidou satellite equipment requirement dictionary,. as shown in table 1. For example, a user may be published comments online about beidou satellite "Navigation positioning of beidou function need to strengthen", this sentence contains some word in high-end equipment requirement dictionary such as "need" and " positioning."At first, establish the requirement dictionary for high-end equipment by the professionals. Then use TF-IDF method to determine the weight of words, and treble the frequency of keywords which appeared in the text. After this process, the text of the IDF value will not change but the TF value will be significantly increased, thus changing the weight of keywords in the text. Using the improved TF-IDF method as the text feature to classify.

Table 1 Beidou satellite equipment requirement dictionary

Hope, reduce, add, increase, could, improve, strengthen, want to , must, request, advice, lack of , instead of, missing, need, function, color, positioning, navigation, timing services, short message communication ability.....

After the machine learning, the original complex text is divided into two categories, namely high-end equipment requirement text $[\mathrm{R}]$ and non requirement text [NR]. High-end equipment requirement text is our text type for further study, and next stage is only deal with the [R] type. So directly. filter out [NR]type in this step.

Step 3: Requirement mining stage. In this step, high-end equipment requirement text [R] will be further mined for requirement. Users on the website published on some requirement information for a high-end equipment products, there will be a certain semantic form, such as on an aircraft forum, "I think the seat space is too narrow, hope to get a bigger seat space." Therefore, we can extract a semantic rule from this sentence[7], "hope $<$ requirement $><$ POSITIVE-ADJECTIVE $>$ ". The "Hope" in the semantic rule is a word that is set up in the key word library, which is equivalent to the trigger word. According to the requirement of all the high-end equipment has been confirmed, extract all the semantic rules of high-end equipment requirements, some of them shown in table 2 . For different high-end equipment products, there may be differences in the requirements of semantic rules. Therefore, on the basis of the specific application background can be designed accurate semantic rules of high-end equipment requirement. So we can use semantic rules that established before to extract specific requirement of a high-end equipment from high-end equipment requirement text [R]. After all these specific requirement of high-end equipment have been extracted, then unified store into the high-end equipment requirement library.

Table2 Aircraft equipment requirements semantic rules

\begin{tabular}{l|l}
\hline \multicolumn{1}{c|}{ Semantic rules } & \multicolumn{1}{c}{ Content simple } \\
\hline Hope $<$ requirement $><$ POSITIVE-ADJECTIVE & $\begin{array}{l}\text { "I hope the plane seat space larger, so } \\
\text { that it is more spacious" } \\
\text { "In all Flight Corporation, I like the } \\
\text { China Southern Airlines' meal, because } \\
\text { I like to eat spicy food " } \\
\text { Like to }<\text {-requirement }> \\
\text { hope that the aircraft can add the WIFI } \\
\text { function" }\end{array}$ \\
add the ability to $<$ requirement $>$ & \\
$\ldots$ &
\end{tabular}


This part applies data analysis technology and machine learning method to mine the requirement information of users on the Internet, and digs out the specific requirement of a high-end equipment product users from miscellaneous information. These requirement information may not be directly express by users, but implied in each big website, so it is meaningful to dig out the requirement information of users from the Internet. I hope that the aircraft can add the WIFI function"

\section{Conclusion}

Globally, the Internet and the big data technology have become an integral part of the high-end equipment manufacturing industry. Due to the radical change of the way people interact, speeding up the formation of a new relationship between enterprise and user, which changes the organization of high-end equipment manufacturing industry and improve the intelligent level of the whole life cycle of products, also promotes the new round of major technological innovation and management innovation in high-end equipment manufacturing industry. For high-end equipment requirement elicitation, which has the characteristics of multi-source, individual, potential under the Internet environment. According to the features of high-end equipment establish requirement elicitation model based on requirement classification. First, we classify the user's need.In this paper, according to users' master degree of requirement, requirements can be divided into instant user requirement and potential user requirement.Then, For instant user requirement, we design a requirement interaction platform based on Internet to get the standardization of the user's individual requirement. For potential user requirement that is, for the Internet's massive user reviews information, using big data analysis technology to carry out potential user requirement mining.Eventually, a complete user requirement program is integrated. This paper presents the ideas that at first make a classification of user requirement, then according to different types of users to take different access technology, which this ideas from a new perspective to study the high-end equipment requirement elicitation, there is a certain extent of innovation and has guiding significance for the development of high-end equipment products. This idea is not only applicable to high-end equipment products, also can be universal. Requirement elicitation for any product can draw lessons from this idea as to obtain a complete, accurate and effective user requirement.

\section{References}

[1] Shani, D., Chalasani, S.. Exploiting niches using relationship marketing [J]. Journal of Services Marketing, 2013, 6(4): 43-52

[2] Webb A. Object-Oriented Analysis and Design 49 Success Secrets-49 Most Asked Questions On Object-Oriented Analysis and Design-What You Need To Know[M]. Emereo Publishing, 2014

[3] Giannozzi P, Baroni S, Bonini N, et al. Quantum espresso: A modular and open-source software project for quantum simulations of materials [J]. Journal of Physics: Condensed Matter, 2009, 21(39): 395-502.

[4] Wu X, Zhu X, Wu G Q, et al. Data mining with big data [J]. IEEE transactions on knowledge and data engineering, 2014, 26(1): 97-107.

[5] Kim S, Yoon B. Developing a process of concept generation for new product-service systems: a QFD and TRIZ-based approach[J]. Service Business, 2012, 6(3):323-348.

[6] Vu P M, Nguyen T T, Pham H V, et al. Mining User Opinions in Mobile App Reviews: A Keyword-Based Approach $(\mathrm{T})[\mathrm{C}] / /$ Ieee/acm International Conference on Automated Software Engineering. IEEE, 2015:749-759.

[7] Iacob C, Harrison R. Retrieving and analyzing mobile apps feature requests from online reviews[J]. 2013:41-44. 